\title{
13. Hipertensión arterial
}

\subsection{Clortalidona y bumetanida en enfermedad renal crónica avanzada: HEBETrial}

Solís Jiménez Fabio, ${ }^{*}$ Valdez Ortiz Rafael, ${ }^{\ddagger}$ Pérez Navarro Lucia Monserrat, ${ }^{\ddagger}$ Cabrera Barrón Ricardo, ${ }^{\ddagger}$ Reyes Tovilla Jorge Eduardo,*

Chida Romero Jesús Antonio ${ }^{\ddagger}$

* Instituto Nacional de Cardiología Ignacio

Chávez. ${ }^{\ddagger}$ Hospital General de México.

Tipo de estudio: Estudio terapéutico

Introducción: En la actualidad, el tratamiento para la hipertensión en enfermedad renal crónica avanzada (ERCA) son los diuréticos de asa; no obstante, su uso crónico produce cambios adaptativos en la nefrona distal que disminuyen su eficacia. Los diuréticos tiazídicos podrían ser útiles en este contexto; sin embargo, las guías actuales no los recomiendan, puesto que no existe suficiente evidencia para recomendar su uso. Objetivo: Evaluar la eficacia y seguridad del uso de diuréticos tiazídicos en pacientes con enfermedad renal crónica avanzada. Metodología: Ensayo clínico aleatorizado doble ciego (NTC03923933) (DI/19/105-B/03/018). Se dividieron a 32 pacientes con ERCA, hipertensión, sobrecarga de volumen y uso crónico de diuréticos de asa en dos grupos: control: bumetanida $4 \mathrm{mg}$ más placebo cada día. Intervención: bumetanida 4 mg más clortalidona 100 mg cada día. Seguimiento a cero, siete y 28 días con bioimpedanciometría, laboratorios y presión arterial. Resultados: Existió diferencia en cuanto a la presión arterial sistémica $(\mathrm{mmHg})$ : sistólica $-26.1 \pm 15.3$ vs $-10 \pm 23.3$ ( $p=0.028$ ); diastólica: $-13.5 \pm 10.7$ vs $-3.4 \pm 11.9(p=0.018)$; media: $-18.1 \pm 8.7$ vs $-5.4 \pm 14.3(p=$ 0.006). Diferencia en sobrecarga de volumen (litros): agua corporal total (ACT): $-4.3 \pm 3.2$ vs $0.075 \pm 1.7(p<0.001)$; agua extracelular (AEC): $-2.5 \pm 1.1$ vs $0.15 \pm 1.2(p<0.001)$; AEC/ACT: $-2.9 \pm 4.7$ vs $-0.2 \pm 1.4(p=0.039)$. Discusión y conclusiones: En pacientes con ERCA, hipertensión y tratamiento crónico con diuréticos de asa el uso combinado de bumetanida y clortalidona puede ser útil para controlar la hipertensión y sobrecarga de volumen. 